
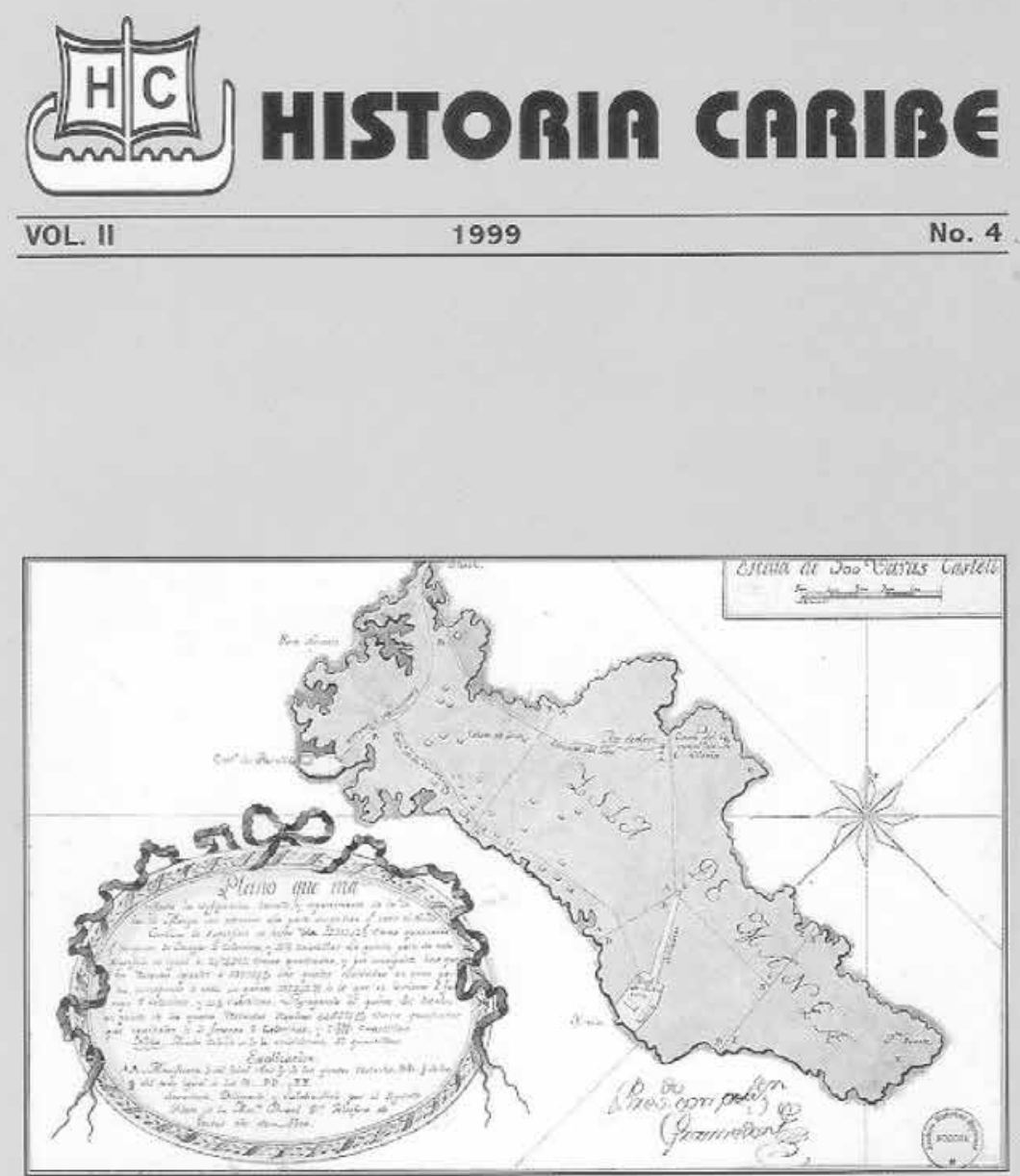

Barranquilla - Colombia

ISSN $0122-8803$

Depósito Legal 3121 - Ministerio de Cultura 


\title{
Canales de riego y canales navegables en la cuenca de México: economía, patrimonio y paisaje en el México porfirista*
}

\begin{abstract}
Alejandro Tortolero Villaseñor
Es profesor en la Universidad Autónoma Metropolitana, Unidad Iztapalapa (México). Correo electrónico: tortoleroalejandro@yahoo.com. El autor es Doctor en Historia y Civilizaciones de la Escuela de Altos Estudios en Ciencias Sociales de París (Francia). Entre sus publicaciones recientes tenemos: "Francois Chevalier y los grandes latifundios: algunas aportaciones de una obra maestra en el contexto de dos tradiciones analíticas", en Boletín de la AFEHC No. 62, (Julio-Septiembre, 2014) y "Agricultural statistics in modern Mexico: a real world or an imagined reality?", en The Golden Age of State Enquiries Rural Enquiries in the Nineteenth Century. From Fact Gathering to Political Instrument, eds. N. Vivier (Blegium: Brepols, 2014), 273-291. Entre sus intereses se encuentran los temas sobre la historia económica, tecnológica y ecológica de México, siglos XVIII al XX.
\end{abstract}

Recibido: 25 de julio de 2014

Aprobado: 16 de septiembre de 2014

Modificado: 11 de noviembre de 2014

Artículo de investigación e innovación

DOI: http://dx.doi.org/10.15648/hc.26.2015.4

Este artículo forma parte del proyecto "Para una historia agraria de México", financiado por la Universidad Autónoma Metropolitana, Unidad Iztapalapa (México).

Esta publicación está bajo una licencia Creative Commons Reconocimiento-Compartir Igual 3.0

\section{(cc) BY-SA}




\title{
Canales de riego y canales navegables en la cuenca de México: economía, pa- trimonio y paisaje en el México porfirista
}

\section{Resumen}

El objetivo de este artículo es el de mostrar la importancia que los lagos y canales tienen todavía en el último tercio del siglo XIX y primera década del XX. Nuestra argumentación señala que entre la arriería y los ferrocarriles existen otras formas de circulación de mercancías representadas por la navegación en canales que serán importantes hasta finalizar el siglo XIX y que se articulan con el transporte moderno de los ferrocarriles. Analizamos cómo los lagos seguían siendo hasta esa época una fuente múltiple de aprovechamiento. Se continuaba sacando partido de sus aguas para la agricultura chinampera y para la nueva agricultura representada por la hacienda introducida por los españoles; se transportaba el agua dulce y cristalina de los manantiales hasta las mesas lo mismo de nobles que de macehuales, en fin los lagos con su flora, su fauna eran centrales en la vida de los pueblos lacustres y de las haciendas de la cuenca de México. Esta centralidad se quebranta con los proyectos desecadores de finales de siglo que dejan su huella en el paisaje.

Palabras clave: Canales, lagos, paisaje, economía.

\section{Irrigation and waterways canals in Mexico basin: economy, heritage and land- scape in the Mexico of Porfirio Diaz}

\begin{abstract}
The main purpose of this article is to analyze the relevance of lakes and canals in the Valley of Mexico in the late nineteenth century and at the eve of the twentieth. We argue that in between the ancient system of mule drivers and the modern system of railroads, we can find navigation systems in that Valley which are very important and complementary to the railroads. Lakes served to achieve a combination of goals: maximize food production related to its resources and to "chinampa" agriculture; prevent floods in urban centers; import fresh water and ensure canoe navigability. Multifunctionality of lakes was broken with the desiccation of the Lake of Chalco practiced at the end of the nineteenth century. We study these disruptions in the regional economy as well as the changes in landscape.
\end{abstract}

Key words: Canals, lakes, landscape, economy. 


\section{Canais de irrigação e canais navegáveis na bacia do México: economia, patri- mônio, e paisagem no México porfirista}

\section{Resumo}

Objetivo deste artigo é o de mostrar a importancia que os lagos e canais ainda têm no último terço do século XIX e primeira década do século XX. Nossa argumentação assinala que entre a arriería e as ferrovias existem outras formas de Circulação de mercadorias representadas pela navegação em canais que serão importantes até o final do século XIX e que articulam-se com o transporte moderno das ferrovias. Analisamos como os lagos continuavam sendo até essa época uma fonte variada de aproveitamento. Continuavam aproveitando suas águas para a agricultura chinampera e para a nova agricultura representada pela fazenda introduzida pelos espanhóis; se transportava a água doce e clara dos mananciais até à mesa dos mesmos nobres de macehuales, enfim os lagos com sua flora e fauna eram centrais na vida dos povos lacustres e das fazendas da bacia do México. Esta centralidade é quebrada com os projetos desecadores do final do século que deixam sua marca na paisagem.

Palavras-chave: Canais, lagos paisagem, economía.

\section{Les canaux dans le bassin de Mexico: économie, patrimoine et paysage à la fin du XIXe}

\section{Résumé}

L’objectif de cet article est de montrer la centralité des lacs et des canaux dans le derniers tiers du XIXe siècle et la première décennie du XXe. Notre propos serait de souligner qu'entre le transport des marchandises à dos d'hommes ou à dos des mules (muletiers), il existe le système de transport lacustre, fait dans des pirogues et des chaloupes et amplement répandu dans le bassin de Mexico jusqu'à l'arrivé des chemins de fer.

Nous soulignons aussi que les lacs ont un usage multiple et varie: on y pratique l'agriculture des indigènes dans ses îles flottants (chinampas), on y transporte aussi ses denrées agricoles, on y boit ses eaux et on y profite de la faune et de la flore. La centralité des lacs est hors question, mais l'assèchement de ses lacs vers la fin du XIXe termine avec cette relation entre les lacs et les hommes. Nous analysons ses traces dans l'économie et le paysage.

Mots-clés: Canaux, lacs, paysage, économie. 
La historia de México está ligada, como lo plasma el escudo nacional, al dominio de un medio lacustre. Tenochtitlán crece a costa de una laguna unida a tierra firme por medio de cuatro calzadas. El esplendor mexicano no se entiende sin el control que sus habitantes tuvieron sobre sus lagos. Para ellos estos eran multifuncionales: lo mismo ofrecían aguas abundantes para beber que aseguraban el desarrollo de su agricultura chinampera o bien las utilizaban para navegar en sus chalupas. Por ello habían desarrollado una serie de obras hidráulicas que eran eficientes para controlarlos.

El sistema hidráulico, además del control de las aguas y de su circulación por medio de calzadas-diques y albarradones, incluía arreglos especiales para facilitar el drenaje, los transportes por agua y la navegación del enorme número de canoas existentes. Entre estos arreglos se mencionan los puertos y los canales o acequias hondas que iban de una ciudad a otra, y en ocasiones penetraban hasta el interior de la zona habitada. El tamaño y profundidad de algunos de ellos permitieron la navegación de bergantines españoles. Estas acequias seguían cumpliendo su función durante el periodo colonial, y hay evidencias de que, en algunos casos al menos, se trataba de obras total o parcialmente artificiales ${ }^{1}$. El grado de conocimientos hidráulicos desarrollados por los indígenas está evidenciado, además, en obras verdaderamente curiosas: el acceso subterráneo por medio de canoas al palacio de los señores de Texcoco; la entrada en canoas desde la laguna salada a los estanques de agua dulce y huertas de Ixtapalapa; los estanques de agua dulce y salada para aves, en los que se podía renovar el agua periódicamente, de la ciudad de México; el acueducto doble de Chapultepec, con el sistema de distribución de agua a los estanques, palacios, viviendas, etcétera.

La paradoja, sin embargo, es que cuando estudiamos los sistemas de transporte tradicionales la mayor parte de los trabajos nos remiten a la arriería o al transporte realizado por tamemes; mientras que cuando estudiamos el sistema moderno las referencias son los ferrocarriles construidos durante el periodo porfirista. Entre los dos no aparecen, como ya lo hemos seña-

1 A. Palerm, México Prehispánico. Evolución ecológica del valle de México (México: Conaculta, 1990), 251. 
lado en otro trabajo, los sistemas de transporte fluvial ${ }^{2}$. Parece, entonces, que una parte importante del medio lacustre representado por el transporte fluvial queda sepultado en los otros usos de los lagos, en la prodigalidad de su agricultura chinampera, en sus obras para captar agua dulce como el acueducto de Chapultepec construido desde 1466 por Nezahualcóyotl y así sucesivamente ${ }^{3}$.

Por ello el objetivo de este artículo es el de mostrar la importancia que estos lagos y canales tienen todavía en el último tercio del siglo XIX y primera década del XX. Nuestra argumentación señala que entre la arriería y los ferrocarriles existen otras formas de circulación de mercancías representadas por la navegación en canales que serán importantes hasta finalizar el siglo XIX y que se articulan con el transporte moderno de los ferrocarriles.

En efecto, la vieja opinión de Salvador Ortiz quien señala en 1929 que, "el arriero con su atajo de mulas, llevando mercancías de una a otra parte, fue el único sistema de explotación, desde la dominación española, hasta poco después de la introducción de los ferrocarriles" prevalece en los estudios sobre los transportes y el mercado ${ }^{4}$. John Coatsworth, por ejemplo, menciona que la inexistencia de ríos navegables y la reducida dimensión del tráfico por lagos que solo beneficia al comercio local y concluye que antes del ferrocarril, las recuas de mulas o burros excedían la carga embarcada en carretas en 18 de las 24 rutas del país hacia $1880^{5}$.

Un problema para avanzar en este campo es el que señala Suárez Argüello

2 Tortolero Alejandro, "Los caminos de agua en la producción y en la producción y el comercio en el Sureste de la Cuenca de México en la segunda mitad del siglo XVIII”, en Esfuerzos y fracasos de la modernización en México: De las reformas borbónicas al porfiriato, ed. R. Liehr (Madrid-Frankfurt am Main: Iberoamericana, 2006).

3 Miguel León Portilla, Antiguas obras hidráulicas en América (España: MOPT, 1988),16.

4 Eduardo Flores Clair, Reseña sobre Clara Elena Suárez Argüello (1997), http://www.h-mexico. unam.mx

5 John Coatsworth, El impacto económico de los ferrocarriles en el porfiriato (México: Era, 1984), 28 y 67; 89; para las carretas véase p. 89. En sus trabajos posteriores el autor reafirma: "Con excepción de algún transporte local en tres grandes lagos situados en las tierras altas y de pequeños tramos de algunos ríos del Golfo que llegaban hasta la base de las montañas, el transporte por agua era desconocido" (Coatsworth, John. Los orígenes del atraso. Nueve ensayos de historia económica de México en los siglos XVIII y XIX. México: Alianza, 1990), 189. 
cuando dice que para Europa, Estados Unidos e inclusive Latinoamérica, existe una amplia y consistente historiografía sobre el transporte y su desarrollo; en México, no obstante, estos estudios no tienen tradición ${ }^{6}$. En efecto, este es un tema inédito que solo ha sido mencionado escasamente en las investigaciones de historia económica que mencionamos en este artículo y solo contados trabajos lo hacen un tema de estudio explícito (Sierra, 1968, Hassig, 1990 y Musset, 1992). Mientras que el primero solo describe las rutas lacustres, los privilegios e invenciones que tratan sobre la explotación de estos canales sin más apoyo que las gacetas y la bibliografía, los otros investigadores se ocupan más de los aspectos económicos y se apoyan en fuentes de archivo. Hassig, por ejemplo estudia el comercio, el tributo y el transporte en el valle de México en el siglo XVI para lo cual se encarga de la relación entre ciudad e hinterland como un tema clave en donde la población, el potencial agrícola de la tierra, las tasas de consumo y la eficiencia de los transportes son elementos relevantes. Musset, en su excelente estudio sobre El agua en el valle de México, dedica un capítulo a los transportes lacustres y la organización del espacio. Allí señala la importancia decisiva de Chalco como puerto de tráfico comercial que no tiene rival alguno ya que Texcoco, "desde antes de la llegada de los españoles... ya no era un gran puerto... la ciudad de Nezahualcóyotl jamás es citada en las crónicas como punto de carga y descarga de la importancia de Chalco". Sin embargo, también señala que evaluar el tráfico de mercancías es difícil ya que, pese a los controles de la administración pública, gran parte de la mercancía escapaba a las estadísticas rudimentarias de la época ${ }^{7}$. Una propuesta de estudio de este escurridizo tráfico la encontramos en las siguientes páginas.

Al mismo tiempo observamos cómo los lagos seguían siendo hasta esa época una fuente múltiple de aprovechamiento. Se continuaba sacando

6 Clara Elena Suárez Argüello. Camino real y carrera larga. La arriería en Nueva España durante el siglo XVIII (México: CIESAS, 1997), 21. Un trabajo sobre los transportes y los transportistas en Nueva Galicia en el siglo XVII confirma esta idea de Suárez. Véase Thomas Calvo. Por los caminos de Nueva Galicia. Transportes y transportistas en el siglo XVII (México: Universidad de Guadalajara, 1997).

7 Alain Musset, El agua en el valle de México (México: Pórtico de la Ciudad de México y CEMCA, 1992), 159. Para el siglo XIX Juan Manuel Durán hace una breve e interesante presentación de algunos proyectos de construcción de canales en Chapala. Juan Manuel Durán. "Los proyectos de construcción de canales en el México de la segunda mitad del siglo XIX”, en Relaciones. 4. (1983): 96-106. 
partido de sus aguas para la agricultura chinampera y para la nueva agricultura representada por la hacienda introducida por los españoles; se transportaba el agua dulce y cristalina de los manantiales hasta las mesas lo mismo de nobles que de macehuales, en fin los lagos con su flora, su fauna eran centrales en la vida de los pueblos lacustres y de las haciendas de la cuenca de México. Esta centralidad se quebranta con los proyectos desecadores de finales de siglo como veremos en seguida.

\section{LA IMPORTANCIA DEL MEDIO LACUSTRE Y SUS CANALES}

El consumo en la Ciudad de México no se explica sin las vías de entrada y sabemos que una buena parte de estos productos circulaban por los caminos de agua de Chalco a la Ciudad de México ${ }^{8}$. Esto es particularmente cierto para el maíz que provenía en su mayor parte de las haciendas productoras de la región de Chalco, que con una producción anual promedio de unas 250 mil fanegas de maíz durante el siglo XVIII, servían para abastecer el consumo anual de la Ciudad que no sobrepasaba la cifra de 200.000 fanegas anuales ${ }^{9}$. Además en sus haciendas, se cultivaban unas 60 mil fanegas anuales de trigo, que era transportado, al igual que el maíz, por medio de canales navegables a la Ciudad de México para ser vendido en la Alhóndiga ${ }^{10}$. Esto no era nuevo, ya desde 1709, se registraban 1.419 canoas que transportaban por los canales de Chalco 97.330 fanegas de maíz y en 1710, 3.463 canoas transportaban 115.120 fanegas por medio de 140 embarcaciones que entraban diariamente a la Ciudad de México por el canal de La Viga.

Esto para no hablar de los productos del lago de Chalco que a través de los escasos datos que nos llegan para otros periodos, suponen un consumo en la Ciudad de México de más de dos millones de patos al año en el siglo XVIII; de un millón de peces en el XVI; las aves migratorias llegaban a la cuenca en un promedio de cinco millones anualmente. Si a esto agregamos los insectos, las serpientes, ranas, sapos y ajolotes, las plantas silvestres co-

8 Véase Alejandro Tortolero, Los caminos del agua... 2006 y Quiroz, Enriqueta. Entre el lujo y la subsistencia... 2005.

9 Enrique Florescano, Precios del maíz y crisis agrícolas en México (México: El Colegio de México, 1969), 184; Charles Gibson, Los aztecas bajo el dominio español (México: Siglo XXI, 1967), 337.

10 Según Gibson, fuera de la provincia de Chalco, las haciendas producían otros productos: trigo, cebada, frijoles, paja, ovejas, reses, caballos y mulas. Charles Gibson. Los aztecas... 337. 
mestibles, algas y tortugas, entonces, estamos hablando de una gran cantidad de productos que consume y distribuye la economía indígena a través de los canales navegables y que escapan al registro de las fuentes ${ }^{11}$.

La explicación de la importancia del transporte por canales es sencilla y tiene que ver con las ventajas comparativas de este transporte. Si se ha señalado que una de las causas del atraso económico de México fue la de no contar con vías navegables que facilitaran el transporte interno de mercancías y hombres ${ }^{12}$. También sabemos que la mejor forma de facilitar el tráfico interno, antes de la llegada del ferrocarril, era a través del sistema de canales navegables ya que un arriero transportaba una carga de 23 kilos a una distancia de 21 kilómetros por día; una mula recorría la misma distancia con 105 kilos de carga, una carreta viajaba de 16 a 19 kilómetros con una carga de 1.800 kilos, mientras que una trajinera se deslizaba 30 kilómetros con una carga de 6.800 kilos $^{13}$. Este era la importancia decisiva de los caminos de agua.

11 Charles Gibson. Los aztecas... 348, 351; Gabriel Espinosa. El embrujo del lago (México: UNAM, 1996), 388. Para el maíz, Alain Musset, El agua en el valle (México: CEMCA, 1992), 154. A falta de mejores datos, permítasenos presentar esta larga cita de M. Payno quien describe la vida en un pueblo mexicano a finales del XIX de la siguiente manera: "No deja de ser curioso saber cómo vive en las orillas de la gran capital esta pobre y degradada población... Unos con su red y otros con otates con puntas de fierro, se salen muy tempranito y caminan hasta el lago o hasta los lugares propios para pescar ranas. Si logran algunas grandes, las van a vender a la plaza del mercado; si solo son chicas, que no hay quien las compre, las guardan para comerlas. Otros van a pescar juiles y a recoger ahuautle; las mujeres por lo común recogen tequesquite y mosquitos de las orillas del lago, y los cambian en la ciudad, en las casas, por mendrugos de pan y por venas de chile.... En la estación de aguas hacen sus pozos y sus atajaderos en el punto que creen más conveniente de las orillas del lago, y recogen su cosecha de sal... Años hay que las lluvias son abundantes y entonces los potreros de Aragón se inundan, las obras hechas para recoger la sal son arrebatadas por las corrientes y el pueblecito queda formando una isla; si las aguas suben, entran en las casas y los habitantes tienen que abandonarlas, se van a Zacoalco o a otros pueblos y haciendas vecinos a acomodarse como peones". Manuel Payno. Los bandidos de Río Frío (México: Porrúa, 1968), 12.

12 Véase para el siglo XVIII. Javier Ortiz de la Tabla, Comercio Exterior de Veracruz, 1778-1821 (España: EEHA, 1978) ya para el XIX, Stephen Haber, Industria y subdesarrollo. El proceso de industrialización en México (México: Alianza, 1992) y John Coatsworth, Los orígenes del atraso. Nueve ensayos de historia económica de México en los siglos XVIII y XIX (México: Alianza, 1990).

13 Ross Hassig., Comercio, Tributo y Transportes. La economía política del valle de México en el siglo XVI (México: Alianza editorial, 1990). Estos cálculos de Hassig son aproximados: para el caso de la carga transportada por las mulas H. Ward señala que en 1823 transportaban 138 kilos a una distancia de 16.7 kilómetros, cosa en la que coincide con Suárez Argüello como lo señala Eduardo Flores Clair, "Reseña sobre Clara Elena Suárez Argüello (1997)" http://www.h-mexico.unam.mx (29/08/2005). Quizá el cambio del XVI al XVIII hace que al aumentar la carga disminuya la distancia. También sabemos que en Chiapas los indios cargadores de café transportaban una carga de cerca de 50 kilos diarios a finales del XIX. Agradezco esta información a Jan Rus. 
Sin embargo, contemporáneos, como el sabio J. A. Alzate no dan cuenta de los canales y solo indican con flechas lo que aparentemente sería la circulación de las canoas (Véase mapa 1) ${ }^{14}$. En efecto, en el mapa de Alzate de 1767 observamos una serie de flechas que indican el tráfico de los lagos del sur hacia la Ciudad de México. Allí aparecen los pueblos circundantes al lago de Chalco que son Santa Catarina, Venta Nueva, Tlapizagua, Ayotla, Tlapacoya, Chalco, Santiago, Ayozingo, Mesquique, Cuitlatetelco, Tuliagualco. En medio dividiendo a las lagunas de Chalco y de Xochimilco aparece Tlaguac. Esta laguna bordea en su parte sur los pueblos de San Gregorio, Nativitas, Xochimilco y San Lorenzo y en su borde oriental los pueblos de Culhuacan, Mexicalzingo, Iztacalco y la Magdalena. En el

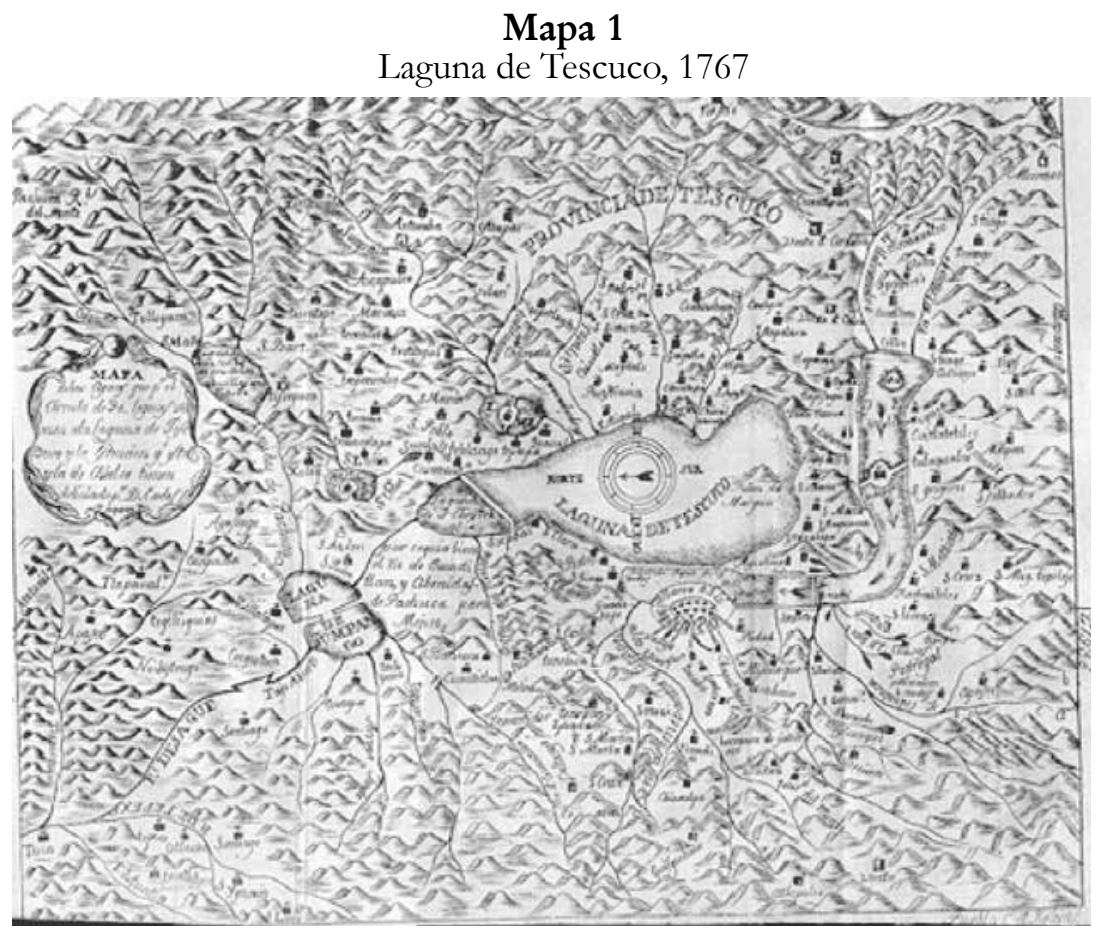

Fuente: Alzate y Ramírez, José A. (1831) Gaceta de Literatura de México. México, Puebla.

Oficina del Hospital de S. Pedro.

14 Otros cronistas solo mencionan la existencia de acequias que corrían hacia la laguna por donde los vecinos de México recibían multitud de productos. Véase Carlos J. Sierra, Historia de la navegación en la Ciudad de México (México: DDF, 1968), 26. Allí el autor también menciona cómo las acequias que había en México en 1637 eran la de Palacio, de un largo de 3.000 varas; la del Carmen, 1095 varas; la de la Merced de 139 varas; la de Tezontlale de 1656, la de Santa Ana de 2840 y la de Mexicalzingo con 2850 . 
camino de Chalco a México aparece la calzada de San Antonio que llega hasta el albarradón de San Lázaro y que forma dos cortes en Culhuacan y en Mexicalzingo para el control de las aguas de la laguna. Como dato interesante en la zona de Iztacalco aparecen representadas las chinampas ${ }^{15}$.

\section{Mapa 2}

Plano de la Laguna de Chalco, 1769

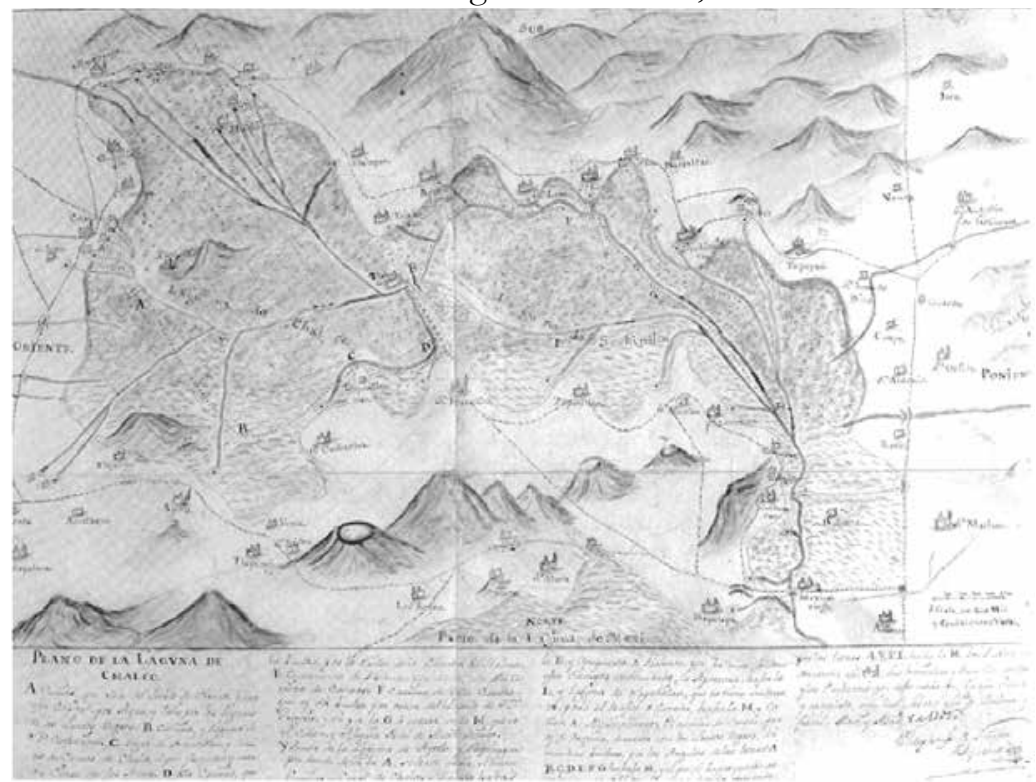

Fuente: Ignacio González Tascón. La ingeniería española en ultramar. España. MOPT.

Sabemos que Alzate había tomado como fuente el mapa que Carlos de Sigüenza había realizado en 1748. Estos dos mapas son la base de nuevas representaciones del territorio de los lagos, de las cuales nos interesa resaltar la que hace Ildefonso de Iñiguez Vejarano en 1769 (Mapa 2). Allí observamos con detalle varias cosas. En primer lugar el escenario principal es el lago con sus caminos de agua, sus embarcaderos y sus asentamientos (pueblos, haciendas y ranchos). Allí observamos que el lago irradia un territorio compuesto de 27 pueblos y 16 haciendas y ranchos que están interconectados por el lago a través de 32 embarcaderos, en un modelo dendrítico cuyo embudo principal se encuentra en el dique de Mexicalzin-

15 José A. Alzate y Ramírez Alzate, "Proyecto para el desagüe de la laguna de Tescuco, 1767”, en El territorio mexicano. (México: IMSS, 1982). 
go. A partir de esta garganta se extienden los canales hacia el sur, encontrándose el puerto principal de entrada en Chalco con cinco embarcaderos y la conexión de los principales pueblos ribereños del sur cada uno con su propio embarcadero. Incluso parece haber una interconexión entre los pueblos del sur a través del sistema de canales, lo que hace que este modelo dendrítico se encuentre descentrado al sur por la presencia de lazos comerciales internos. La mitad norte, en cambio, aparece más ligada a los canales principales y a la ruta carretera entre México y Puebla que a un sistema de canales horizontales.

Chalco, en este contexto, aparece como el principal puerto de entrada de las mercancías llegadas por los caminos carreteros de tierra caliente y por las rutas interiores que ligaban a sus pueblos y sus haciendas con la cabecera del distrito y con sus embarcaderos: uno en Ayotla, dos en Ixtapaluca, cinco en Chalco, uno en Ayotzingo, otro en Huitzilcingo y uno más en Mixquic. Allí están pues los nueve embarcaderos que encontramos en los Informes de los Visitadores de la época, además del ya mencionado de Santa Bárbara, están el de la Colecturía de la Santa Iglesia Catedral Metropolitana, el de Retana, el de San Joseph, el de Gordon, el de San Antonio Abad, el de San Ysidro, el de la Soledad y el de San Joseph ${ }^{16}$. Es importante resaltar que en este momento el canal principal parte de Chalco pasando al norte de Xico, muy cerca de Tlapacoya para de allí ir descendiendo al sur, por Tequimistlán, hasta alcanzar el dique de Tláhuac. De allí va bordeando los pueblos del sur por el Lago de Xochimilco y a partir de San Gregorio gira hacia el norte hasta alcanzar al pueblo de Tomatlán, uniéndose enton-

16 En efecto en el pueblo de Chalco estaban los siguientes. El embarcadero de la iglesia Catedral Metropolitana que era administrado por don Domingo Estevanes quien recibía el maíz de los diezmos de los agricultores de Chalco y los remitía a la alhóndiga de la iglesia en la Ciudad de México. El de San Joseph era administrado por don Miguel Acosté y su dueño era Santhiago García. El de Retana, propiedad de la hacienda del mismo nombre de doña Yzabel Gil de Rosas y administrado por don Joseph Araújo. También estaba el de Gordon, pero ya arruinado en el que su propietario Francisco Luzuriaga, declara solo embarcar leña. En el pueblo de Ayotla había dos: el de San Antonio Abad propiedad de Bonifacio Antonio Lopes y el de la hacienda San Ysidro, propiedad del hacendado don Joseph Narbarte y administrado por don Juan de Herrera. Luego en el pueblo de Ixtapalucan estaba el de Santa Bárbara propiedad de doña Juana Theresa de Cifuentes y administrado por don Nicolás de Horta. En el pueblo de Ayotzingo estaba el embarcadero de la Soledad propiedad de don Lorenzo López y Arteaga y el de San Joseph de el Agueguete, propiedad de la hacienda del mismo nombre de doña Antonia Brizuela y administrado por don Joseph Antonio Guerrero. 
ces con el canal de Xochimilco y el de La Noria hasta llegar a la garganta de Mexicalzingo. En 1769 este recorrido parecía largo, sinuoso y peligroso, sobre todo entre Tequimistlán y Mixquic donde se señala que el camino se cierra frecuentemente por los aires. Por ello se propone un camino más directo que parte en dos a los lagos de Chalco y Xochimilco, pasando al sur de Xico, para alcanzar en forma más directa a Mixquic, evitando así los peligros de los vientos, y siguiendo desde Mixquic por la mitad norte del lago hasta alcanzar a Tomatlán.

Esta situación es aún más clara en las representaciones cartográficas del siglo XIX. En efecto, con los proyectos de navegación por la laguna tendremos más detalles sobre la navegación por canales que sirven a la comparación. Allí encontramos que los caminos de agua se formaron por medio de canales navegables, de los cuales el principal partía del pueblo de Chalco, atravesando el Lago de este a oeste, pero no en línea recta, llegando a Xico, de ahí a Tláhuac, donde se dividían las aguas del lago de Chalco y Xochimilco por medio de un dique. Enseguida se recorría el pueblo de Tomatlán y de ahí se unía al canal de la Viga que de sur a norte bordeaba los pueblos de San Francisco, Mexicalcingo, San Juanico, Iztacalco, Santa Anita hasta llegar al centro de la ciudad en donde se desembarcaban los cereales para ser almacenados en las trojes de la Alhóndiga (Mapa 2).

La distancia total que se recorría era de aproximadamente 13 leguas por caminos tortuosos que seguían las embarcaciones en unas 16 horas de viaje. El hecho de que el camino fuera así obedecía a que al formar sus chinampas, los campesinos llevaban a pastar sus ganados en tiempos de secas y había terrenos que ya sea por el peso del ganado o por otros factores se desprendían de la "cinta" principal formando "bandoleros" o fracciones que mudaban de lugar. Estos "bandoleros" impedían la correcta circulación de las embarcaciones y además la vegetación de los lagos también se acumulaba en ciertas partes, lo cual impedía el tráfico en línea recta de las canoas. Por ello, Orozco y Berra afirmaba que los indios se habían visto obligados a romper en los lugares convenientes, canales o acalotes, que no siguen la línea recta, sino que se desvían de esa dirección, formando un trayecto más largo; esto repercutía en mayor esfuerzo y tiempo. Para 
compensar esto, el tráfico se hacía generalmente por las noches para evitar el desgaste de los remeros por las altas temperaturas ${ }^{17}$.

A este canal principal se unía el Canal de San Lázaro que conectaba a la ciudad con el lago de Texcoco y también al interior del lago de Chalco había pequeños canales o acalotes que servían para conectar a los embarcaderos vecinos como el de Santa Bárbara que pasaba por Tlapacoya para unirse en la isla de Xico al canal principal. El cambio fundamental, como se observa, es que las canoas bordean a Xico por el sur y de allí siguen prácticamente el mismo camino colonial, evitando los temibles vientos de Tequimistlán ${ }^{18}$.

\section{Los CANALES EN LA PRODUCCiÓN Y EL TRÁFICO DE MERCANCÍAS. De la Colonia al porfiriato}

\section{a. Maíces, canoas y hacendados durante la Colonia}

El comercio de mercancías entre Chalco y la Ciudad de México era intenso: azúcares y frutas de la Tierra Caliente; carbón, leña y madera de las montañas de la Sierra Nevada; flores, frutas y hortalizas cultivadas en las chinampas; peces, aves acuáticas y productos de la laguna; pero sobre todo una gran cantidad de cereales cultivados en las haciendas y pegujales de la región de $\mathrm{Chalco}^{19}$.

En efecto el alimento principal de la gente pobre en la Ciudad de México y en el país entero era el maíz. En torno a sus cosechas se ajustaba la vida y el calendario de la gente. Una mala cosecha de esta semilla y estallaban terribles crisis de subsistencia. Para hacer frente a esta demanda maicera, las haciendas y las tierras de Chalco se habían convertido en el princi-

17 Manuel Orozco y Berra, Memoria para la Carta Hidrográfica del valle de México (México, 1864), 163.

18 Es curioso observar que en los documentos de los pueblos como el de Ixtayopan hay constantes referencias a las aguas y a los vientos de "esa gran laguna". AHTSJDF. Copia de los títulos de tierras de los naturales del pueblo de San Juan Ixtayopan.

19 Lucía Martínez, "Máquinas, naturaleza y sociedad en el distrito de Chalco, Estado de México a finales del siglo XIX”, en Tierra, agua y bosques: historia y medioambiente en el México Central. (coord.) Alejandro Tortolero (México: CEMCA-I. Mora-UdeG, 1996), 254. 
pal centro productor; prácticamente en el monopolio que abastecía a los voraces consumidores de la Ciudad de México $^{20}$. La región contaba con ventajas especiales: su proximidad a la ciudad, su abundante población, su tráfico por canales, sus tierras llenas de humus arrastrado por los limos de las aguas del lago y detritus vegetales, en fin sabemos que la hacienda comercial productora de maíz, llegó a su máximo desarrollo en Chalco en la época colonial.

En efecto, apenas había indicios de falta de maíces en la Alhóndiga e inmediatamente los oficiales reales recibían las órdenes de ir a Chalco para evitar la regatonería y el extravío de maíces; en su lugar, debían establecer medidas para hacer venir todos los maíces de Chalco "en derechura" a la Alhóndiga. Gracias a sus informes podemos conocer con detalle la producción y el intercambio de maíces por los canales de Chalco.

En la segunda mitad del XVIII, de acuerdo a nuestros datos, raro fue el año en que estos hacendados no introdujeron, de manera oficial, más de 40 mil fanegas de maíz; en cambio hubo diez años en que llegaron casi o sobrepasaron las 60 mil fanegas y seis años en los que enviaron más de 100 mil fanegas. Por ello las estimaciones ya apuntadas de Gibson de que un rendimiento promedio de las haciendas de Chalco en el XVIII era de 250 mil fanegas en 46 haciendas $^{21}$. Estas explotaciones se servían de canoas que eran grandes y pesadas embarcaciones de madera accionadas por uno o más remeros generalmente indígenas. Estos, ayudándose de un palo largo que enterraban sobre el suelo lodoso, propulsaban el movimiento de las embarcaciones que tenían nombres como "San Cayetano", "San Juan Nepomuceno", "San Ygnacio", "Ysasi", etc. En el mes de mayo del mismo año de 1760, por ejemplo, estas embarcaciones habían transportado 12.528 fanegas de maíz a través de los puertos de Chalco. Las canoas debían viajar con una boleta indicando el puerto de embarque, la cantidad de productos transportados y el destino final, pero había muchas canoas

20 Enrique Florescano, Breve historia de la sequía en México. (México: Conaculta. 2000), 102 y Charles Gibson, Los aztecas bajo el dominio...

21 Charles Gibson, Los aztecas... 337. Florescano señala que la media de maíz vendido en la Alhóndiga en años de buenas cosechas fue de 36.680 fanegas, mientras que en los de malas cosechas fue de 110.144. Enrique Florescano, Precios del maíz... 19. 
que viajaban sin boleta. En efecto, con pretextos como el de que transportaban artículos libres del pago de la alcabala, como los productos de la tierra, o que eran para el diezmo de la Santa Iglesia, cada mes había un tráfico de varios miles de fanegas de maíz que no eran transportados con boletas. En ese mes de mayo se reportaron cerca de cinco mil fanegas extraviadas y solo 7.538 llegaban directamente a la Alhóndiga. Por ello las medidas adoptadas por la Corona de enviar al licenciado Francisco del Barrio para vigilar que el tráfico se realizara sin extravíos y directamente hacia la Alhóndiga. El castigo para los infractores, contrabandistas de agua dulce, era de "apercivimiento y dos mil pesos de multa"22.

A juzgar, entonces, por esta información el tráfico anual, en años de malas cosechas era cercano a las 150 mil fanegas de maíz, de las cuales una tercera parte no llegaba a la Alhóndiga, utilizando medios como desviarlos por Texcoco, hacerlos pasar como maíz del diezmo o circularlos por los canales en claro contubernio con los guardas de las garitas.

\section{b. Transformaciones durante el siglo XIX: los primeros proyectos}

Un siglo después los canales siguen siendo un elemento muy dinámico para enlazar el hinterland agrario a la Ciudad de México. La acequia real seguía conectando a Chalco con la Ciudad de México y se hacen nuevos proyectos para la navegación fluvial.

En efecto, entre 1750 y 1850 los canales experimentan un siglo de apogeo en algunos países europeos como Francia. Allí se construyen más de 4.800 $\mathrm{km}$ de canales que unidos a los existentes daban una suma de unos 11.000 kilómetros de vías acuáticas ${ }^{23}$. Los canales alemanes nunca fueron más de

22 Archivo General de la Nación (AGN) Alhóndigas Exp. 4. Para el contrabando en el siglo XVIII véase Ruggiero Romano, Moneda, seudomonedas y circulación monetaria en las economías de México, (México: FCE-COLMEX, 1998), 35-101. Para el XIX ver Walter Bernecker, De agiotistas y empresarios. En torno de la temprana industrialización mexicana (México: UIA, 1992) y Schmuggel, Illegale handelspratiken in (Mexico: DES, 1988), 19.

23 Kip, “El transporte y la construcción, 1300-1800”, en M. Kranzberg, y C. Pursell. Eds. Historia de la tecnología. La técnica en Occidente de la prehistoria a 1900 (España: G. Gili, 1981). Pinon da otras cifras: antes de 1750 se habían construido $617 \mathrm{~km}$; entre 1750 y 1813 se construyen $570 \mathrm{~km}$, mientras que entre 1814 y 1913 se construyen 4.044, además de transformar $1.519 \mathrm{~km}$ a una mayor dimensión. Pinon, Un canal, des cannaux (Paris: Ed A \& J Picard, 1986), 2. 
la mitad de los franceses conectando el Rin con el Elba. En Gran Bretaña las vías navegables interiores tenían una longitud de 6.800 kilómetros en 1858. En Rusia, en cambio, alcanzaban la suma de 80.500 kilómetros $^{24}$. En el continente americano, en los Estados Unidos había un total de 6.000 kilómetros de canales hacia 1850, mientras que en México se continuaba navegando por los canales prehispánicos y coloniales que hemos descrito y que no alcanzaban a remontar un centenar de kilómetros.

La ciudad de México sin duda la más importante de la América hispánica y solo era superada en número de habitantes por ciudades norteamericanas como Boston, Filadelfia o Nueva York a mediados del siglo XIX ${ }^{25}$. A semejanza de esta gran ciudad emergente de Nueva York que había construido entre 1817 y 1824 el canal del Aire con una longitud de 585 kilómetros para llevar el grano desde los grandes lagos hasta Nueva York, incorporando una región interior de enormes potencialidades y haciendo de esta ciudad por primera vez la gran metrópoli financiera y económica de la Unión Americana ${ }^{26}$; en el caso mexicano la Ciudad de México gravitaba como centro económico y en esta situación el tráfico por los canales de agua tenía la enorme importancia que ya hemos señalado. Gracias a los canales se podía abastecer a la población de la Ciudad de México evitando hambres y descontento, pero también se podía llevar agua de los manantiales de Ayotzingo a las mesas de nobles y pudientes como una multitud de productos venidos de tierra caliente y hasta las nieves de los volcanes eran transportadas para el consumo urbano, como medicina para bajar las fiebres, como artículo de consumo suntuario en las heladerías, como forma de enfriar las bebidas cuando el calor era acuciante, en fin, el tráfico de productos era variado e incluso la madera llegaba diariamente a la ciudad en barcos y trajineras que navegaban por la gran acequia real.

El problema era que el sistema de canales tenía serios obstáculos para

24 T. K Derry y Trevor I Williams eds., Historia de la tecnología desde 1750 hasta 1900 (México: Siglo XXI, 1977), 637.

25 Boston tenía en 1850200 mil habitantes, Filadelfia 400 mil y Nueva York 700 mil. Paul Bairoch, De Jericho a Mexico. Villes et économie dans l'histoire, (Arcades: Gallimard 1985), 399. La Ciudad de México tenía 170 mil habitantes en 1852 y 200 mil en 1857. Keith A. Davis, "Tendencias demográficas urbanas durante el siglo XIX en México”, Historia Mexicana, (1972): 501.

Derry y Williams, eds. Historia de la tecnología, 644. 
cumplir su cometido. A menudo las hierbas los cubrían haciendo impracticable la navegación. En la época de fuertes vientos las estacadas que servían para proteger sus contornos se desprendían impidiendo la navegación y la caída de puentes se señalaba como otro obstáculo frecuente al paso de canoas. Todo esto para no señalar las constantes quejas por el robo a las canoas. Hay que señalar que la geografía de los canales era una invitación para que prófugos y personas fuera de la ley se refugiaran en un territorio apto para pasar inadvertido.

Por todo lo anterior, era necesario encontrar sistemas más eficaces para el transporte lacustre y a esto se abocan los proyectos de varios empresarios. El primero es presentado por Mariano Ayllón en 1853 para navegar por todas las lagunas, canales y acequias abiertas o que se abrieran en el valle de México. Se le concede el privilegio por 15 años, pero en 1854, ante diversos problemas, deciden interrumpir los trabajos de canalización y navegación. Sin embargo en 1865 el señor Ayllón se asocia con A. Knight y se solicita un nuevo privilegio para la navegación a vapor en las lagunas de Chalco y Xochimilco. Las razones que argumentan para fundamentar su petición son la economía de tiempo en el transporte de pasajeros, el tráfico expedito de mercancías y el menor costo en el transporte. Querían hacer de Chalco el depósito de los productos de tierra caliente "que se despachan al interior del Imperio". La respuesta del encargado de la Sección 5a. del Ministerio de Fomento es que se niegue el privilegio ya que argumenta que estas ventajas las traería el ferrocarril: "los grandes beneficios que se hacen valer con la rapidez de la comunicación, la baratura del flete y la fácil introducción de frutos y efectos que vienen de Tierra caliente; pues bien, todos estos beneficios y con mayor ventaja se obtendrán con el camino de fierro que se está construyendo de esta capital al pueblo de Chalco"27.

Alejandro Knight no queda contento con esta respuesta y el 12 de septiembre de 1865 solicita nuevamente le sea concedida la autorización para la navegación en las lagunas por medio de buques de vapor. Se compromete a comenzar el servicio en un año, a construir buques que no perjudiquen 
la navegación por otros medios y a conformarse con el reglamento de policía. El Gobierno Imperial accede y otorga el permiso correspondiente ${ }^{28}$.

El permiso se concede el mismo año en que se analiza la petición de Jorge Hammeken, arrendatario de la hacienda de Buenavista, quien recurre a su experiencia "de haber visto pasar botes en los Estados Unidos con sus cargamentos en un plan inclinado, de una altura muy superior a la que existe entre las lagunas de Xochimilco y Texcoco", para establecer una comunicación por el canal de Chalco y el de Garay. En su calidad de Director de Aguas del Valle, Francisco de Garay sostiene que las propuestas de Hammeken son dignas de aprobación y el 26 de enero de 1866, el emperador Maximiliano, desde Cuernavaca, establece el decreto que autoriza el proyecto propuesto ${ }^{29}$.

Existían otros proyectos como el de Benito León Acosta quien solicita en 1859 le sea concedida la apertura de un canal en el camino que conduce de México a Chalco para la navegación de canoas tiradas por caballos ${ }^{30}$. Benito León era un ingeniero topógrafo que se asocia con los empresarios Cayetano Rubio y Luis G. Barreiro para lograr sus propósitos. El canal que proponen tendría una distancia de 6 leguas, en lugar del antiguo de 13, posibilitando el recorrido de México a Chalco en seis horas en lugar de las 16 o 20 que se empleaban por el antiguo canal (Mapa 3).

El documento que acompaña la petición es importante en virtud de que allí aparecen algunos datos sobre los costos y los beneficios que se esperan por la apertura del canal. En el primer rubro suponen que los gastos por la apertura de un canal con cinco pies de profundidad, siete varas de latitud y seis leguas de distancia, serían no mayores a los 80 mil pesos. La forma de obtener el capital fue a través de la creación de "Bonos del canal de Chalco" por un valor de 120 mil pesos, en acciones de 500 y 250 pesos. Es decir, se trata de empresarios que se instalan en la modernidad de las so-

28 En el decreto se asienta: "En atención a las ventajas que traerá al comercio y en general al tránsito de pasajeros el establecimiento de buques de vapor en el canal de México a Chalco y en vista de la solicitud que en este sentido han presentado D. Alejandro H. Knight y Ca., se concede a estos señores la autorización respectiva". AGN. Fomento, Desagüe, vol.18./Exp. 42.

29 AGN. SCOP: Vol.18/Exp. 39.

30 AGN. Fomento. Desagüe, Vol. 48/Exp. 50. 


\section{Mapa 3}

Caminos y canales de navegación de los lagos de Texcoco, Chalco y Xochimilco, 1864

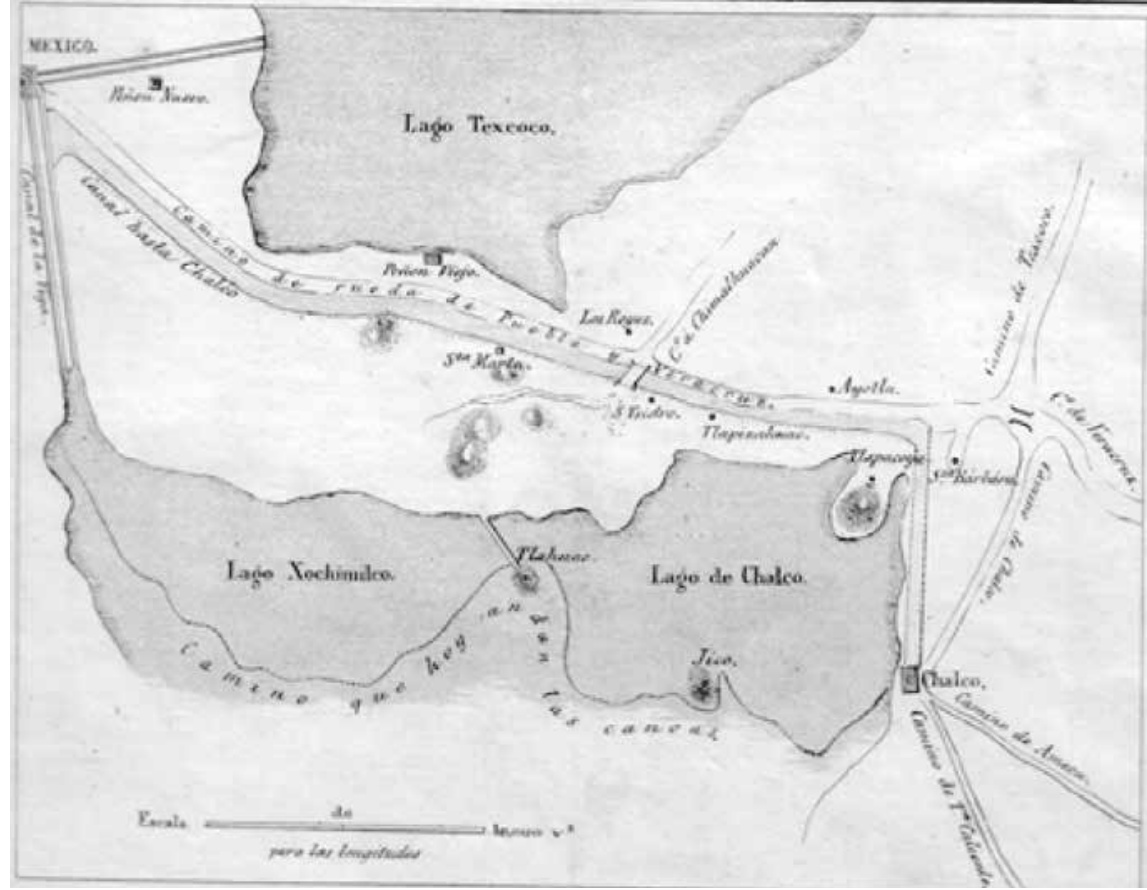

Fuente: Orozco y Berra, Memoria para la carta hidrográfica del Valle de México.1864

ciedades por acciones y que desde su óptica empresarial suponen que sus accionistas recuperarán el capital en el transcurso de unos cuantos años.

En efecto, según datos de la Aduana de México, los fletes recaudados anualmente ascienden a 50 mil pesos. El movimiento de pasajeros es de $\$ 20.940$, lo cual suma $\$ 70.940$ y aunado a los efectos que ingresan por la garita de San Lázaro del orden de $\$ 5.000$ hacen un total de $\$ 75.940$. Si los costos de administración, de mantenimiento y de arrendamiento del terreno suman 10 mil pesos anuales, entonces, la utilidad para la compañía sería de $\$ 70.000$ que era más del $50 \%$ del capital inicial.

Es probable que el interés de estos empresarios tuviera que ver con el ambiente cultural de la época. No en vano desde 1859 una compañía francesa bajo la dirección de Fernando de Lesseps había comenzado la construcción del canal de Suez y diez años más tarde se inaugura el canal con 148 kilómetros de longitud, 8 metros de profundidad y 22 de anchura. Una 
década más tarde circulaban por el canal tres millones de toneladas que se convirtieron en once en $1901^{31}$.

Sin embargo el personaje que va a consolidar todos estos proyectos de navegación por las lagunas de Chalco y Xochimilco y la introducción de vapores será Iñigo Noriega.

\section{c. Canales y desecación al finalizar el siglo XIX: el proyecto de Noriega}

El proyecto de I. Noriega lo hemos descrito en otros trabajos. En ellos hemos estudiado cómo Noriega desea imponer un proyecto agrícola a costa de la desecación del lago de Chalco. En efecto en las partes lacustres observamos la subdivisión de las tierras de la Negociación de Xico. Allí se afirma que existen 9.154 hectáreas de tierras desecadas con capa de turba vegetal, 1.524 hectáreas de riego en la Hacienda de La Compañia, 270 hectáreas de tierras de riego y enlame que se dedicaban al cultivo de la alfalfa y árboles frutales, 2.894 hectáreas de tierra de loma y monte y 312 hectáreas del Peñón de Xico que forman un total de 14.154 ha de la Negociación. En las partes lacustres se construyen cerca de $400 \mathrm{~km}$ de canales interiores de cinco metros de ancho que se utilizan para drenaje y para irrigar las tierras además de servir como medio de transporte para pequeñas embarcaciones que sacan los productos de la hacienda. Estas mercancías eran esencialmente maíz, leche y frutos, pero no contento con esta producción Noriega introduce una ladrillera para enviar materiales de construcción que serán necesarios para urbanizar sus terrenos de la Colonia de La Viga en la Ciudad de México, pero también para otras urbanizaciones ${ }^{32}$.

En suma los recursos de esta parte lacustre estaban bien aprovechados y sobresale el conocimiento que los Noriega tenían de las aguas y del sistema hidrográfico. No solo de las que formaban el lecho del lago donde

31 Derry y Williams, eds. Historia de la tecnología... 650.

32 En 1914 por ejemplo el producto del maíz era de $\$ 425.000$, el de los establos de \$115.000, el del pulque \$12.000, mientras que en la ladrillera se obtenía \$60.000. Noriega paper’s. NL Benson-UT. Austin. Las estrategias para vender ladrillos de Noriega pueden documentarse en Archivo Histórico Grupo Carso (AH-Carso). CDLIV.1.1883.52.13900. 
mencionan 233 millones de metros cúbicos, sino de aquellas que alimentan este lago ${ }^{33}$. Por ejemplo las aguas del río de Tlalmanalco se conocían con detalle ya que estaban mercedadas desde la época colonial a la hacienda de La Compañía, al pueblo de Chalco y al de Tlalmanalco. Noriega hace mediciones del caudal del río asentando que acarreaba un aforo de 21 surcos y 23 y medio reales, de los cuales 14 y medio surcos estaban mercedados a su hacienda de la Compañía; el pueblo de Chalco gozaba de 3 surcos y medio y el de Tlalmanalco de 2 surcos y 28 y medio reales ${ }^{34}$. Como se observa la hacienda gozaba del $66 \%$ del total de las aguas del río y esto no dependía de la importancia de la población sino de los recursos productivos puestos en juego. Mientras que Chalco tenía una población de tres mil habitantes al finalizar el XIX, la Compañía apenas tenía 270, 143 hombres y 127 mujeres. Sin embargo esta hacienda necesitaba el agua para el cultivo de sus tierras, para sus establos de ordeño, para el cultivo de la alfalfa y los piensos del ganado y así sucesivamente ${ }^{35}$. Por ello establece acuerdos con otros usuarios del agua como la Fábrica de Papel de San Rafael y la textilera de Miraflores, así como con los habitantes de los pueblos mencionados ${ }^{36}$.

Un segundo ejemplo es el del río Temamatla o Ameca que también vertía sus aguas en el lago de Chalco por el lado de la negociación agrícola de

33 Alejandro Tortolero, Notarios y agricultores. Crecimiento y atraso en el campo mexicano, 1780-1920 (México: Siglo XXI, 2008), 125.

34 Un surco equivalía a 6 litros y medio, por lo tanto a Chalco le corresponden 1.365 litros y a Tlalmanalco 1242, sin embargo este último pueblo utilizaba 1.581 litros lo que le hacía tener un excedente de 338 litros y eso lo anota Noriega. Noriega laso paper's. UT Austin. Enero 25, (1912).

35 Su inventario en 1897 nos informa que las principales riquezas de la explotación eran los magueyes, ladrillos, ganado y leña del bosque. Alejandro Tortolero, De la coa a la máquina de vapor..., 259.

36 Se afirma que, "las aguas se convierten en insalubres debido al mal uso que hacen de ellas las Fábricas de San Rafael con la elaboración de papel y la Fábrica de Alfombras El Caballito, ubicada en Tlalmanalco, propiedad del Sr. Turin. Este señor ha manifestado en la visita de ojos que hicimos que, convenía en que las aguas se ensucian y se descomponen; que él no estaba en condiciones de instalar la maquinaria requerida para evitar esa descomposición y que por lo tanto prefería no hacer uso de las dichas aguas para Tintorería, limitándose únicamente a usarla como fuerza motriz. En tal virtud concurrirá a esta escritura para el efecto indicado. La Fábrica de San Rafael no está en las mismas circunstancias por ser muy importante el capital invertido en esa industria. Esta negociación no solo descompone las aguas sino que dispone de ellas para el uso de fabricación en cuya operación no solo consume sino que desperdicia". Sin embargo permiten a San Rafael el acceso al agua a cambio de construir tuberías que conduzcan las aguas desde los tanques de San Rafael a los pueblos vecinos de Chalco y Tlalmanalco por medio de entubación de hierro y en buenas condiciones, sin contaminación. Noriega Paper's. NLBenson Library-UTAustin "Aguas del río Tlalmanalco". 
Xico. Este río es observado desde su nacimiento en la vertiente norte del Popocatépetl producto de los deshielos del volcán y estudian su cauce desde 1897 hasta 1906 ya que forma parte del proyecto de desecación del lago. Cada año miden los máximos y los mínimos de su aforo y estudian la posibilidad de construir una presa para almacenar sus aguas ya que en temporadas de lluvia originaba frecuentes inundaciones en la negociación agrícola de Xico. Proponen construir una presa en la parte alta en el paraje denominado "Peaje" para almacenar más de 16 millones de $\mathrm{m}^{3}$ a través de una cortina de 32 metros de altura, de 286 metros de longitud de la corona y de 5 metros de ancho en la corona. El estudio es tan detallado que no vacilan en compararla con obras similares en otros lugares del mundo ${ }^{37}$.

Este lago de Chalco era usufructuado por los habitantes de los pueblos ribereños quienes señalaban que desde "tiempo inmemorial" sus pobladores se beneficiaban de sus aguas para irrigar sus tierras y construir chinampas, además de comer peces y fauna acuática del lago. Los tules les servían para construir sus casas y fabricar sillas y petates para dormir. La centralidad del lago en la economía campesina era evidente. Los Noriega, aprovechan la concesión para usar las aguas del lago dictada por Porfirio Díaz en 1895 y declaran todas las tierras desecadas como propiedad privada de la Negociación Agrícola de Xico.

La propiedad de las aguas y canales, antes comunal, se convierte al finalizar el siglo en propiedad de una empresa que había invertido trece millones de pesos en 1913 para el drenado. La Negociación construye 203 kilómetros de canales. Uno de 16 kilómetros, dedicado a la conducción de las aguas del lago de Chalco al de Texcoco. Otro de 18 kilómetros de extensión y 12 metros de ancho, que sirve para llevar el líquido de los manantiales de la parte sur de la antigua laguna de Chalco a la de Xochimilco y para conducir las aguas que en tiempos de lluvias proceden de las cumbres de la Sierra Nevada. Uno más al norte de la Hacienda de Xico pasando por los pueblos de San Lucas, Tlapacoyan, Ayotla y Tlapisahua de 14 kilómetros

37 Mencionan por ejemplo la presa Indian River de Nueva York, la de Bahgtur en India, al de Bear Valley en California, la de Furens en Francia, Villar en España y muchas otras. Noriega paper's. NL Benson. UTexas-Austin. Informe que acompaña el proyecto de presa de almacenamiento en el río de San Juan de Dios. Francisco G. Moctezuma. Xico, octubre de 1909. 
por 8 metros de ancho que sirve para recoger las aguas que en tiempo de lluvias bajan de los montes de Tlalmanalco, González, La Compañia, Zoquiapan para mandarlas directamente al Lago de Texcoco. Y el resto de los canales, que suman 154 kilómetros tienen por objeto el drenaje y el riego de los terrenos y la traslación de las cosechas a los puntos que convenga. Así se terminaba una relación milenaria de los hombres de la región con sus lagos y se inauguraba la era de la gran hidráulica que habría de marcar un siglo de castigo ecológico ${ }^{38}$.

Si en una primera etapa, entre 1895 y 1902, la desecación se hace en la parte sur de la laguna, los Noriega se dan cuenta que subdividiendo las tierras de Xico y desecando paulatinamente la parte norte pueden aprovechar espacios cada vez más productivos. Por eso en un segundo momento comienzan con la desecación de la parte norte y es allí donde se asocian con los inversionistas franceses para terminar estas obras . Establecen una subdivisión en seis lotes, de los cuales hasta 1906 se explotaban como sigue. El lote uno estaba formado por la hacienda de la Compañia con la producción que ya hemos mencionado: ladrillos, leche, maíz. El lote dos era el del antiguo lago convertido en Negociación Agrícola de Xico con terrenos de primera calidad y cosechas de maíz al 200 por 1. En el cerro de Xico se obtenían materiales para construcción y también se crea un establo lechero. Los lotes tres y cuatro en el antiguo lago apenas se estaban preparando en 1906, en cambio el cinco ya estaba siendo explotado casi en su totalidad. Finalmente el lote seis, también sin cultivar, tenía oficinas para almacenar cosechas, habitaciones para jornaleros y se estaba construyendo otro establo.

La incorporación de los terrenos se reflejaba en las utilidades de la Negociación. Se crea en 1897 y al año siguiente ya ofrece utilidades por $\$ 53.521 .83$, en 1900 se incrementan a \$74.240, en 1901 alcanzan los \$152.832; en 1902 el incremento es muy leve apenas llega a $\$ 169.992$ y en 1903 no hay utilidades debido al incendio de la troje principal y a las heladas prematuras e inesperadas de los días 21, 22 y 23 de junio que reducen la cosecha a la tercera parte. En 1904 otra vez las utilidades se incrementan a \$219.165

38 F. Herin define a la gran hidráulica, "como un conjunto de innovaciones tecnológicas que contribuyen al control eficaz y de envergadura de los recursos hidráulicos", en Agua y Modo de Producción. Lemeunier, Pérez Picaso et al. (Barcelona: Crítica, 1990), 61. 
utilizando el $33 \%$ de los terrenos de la negociación y en 1905 el cultivo alcanza el $42 \%$ de las tierras con utilidades por $\$ 312.956^{39}$. Finalmente en 1908 de acuerdo a los reportes de A. Genin, miembro del Consejo de Administración de la Sociedad Financiera para la Industria en México, que había hecho importantes préstamos a Xico establece que la Negociación vende 38 mil pesos en leche, 14 mil en pulque, 130 mil en trigo y alfalfa y un 1.230.000 de maíz, total 1.412 .000 pesos, aprovechando el $60 \%$ de los terrenos drenados ${ }^{40}$. La Negociación estima que cuando se aprovechara el $100 \%$ de las tierras drenadas el valor de la producción anual se incrementaría a dos millones de pesos.

\section{Canales y paisaje}

En el siglo XIX asistimos a una profunda transformación en la región de Chalco que podemos resumir de la siguiente manera: esta gran revolución agrícola en la cuenca de México, como lo hemos señalado, pasa de los embarcaderos a los ferrocarriles, de los trabajos con coas y azadones a la mecanización, de la antigua a la gran hidráulica, de la cultura extensiva a la intensiva donde la asociación entre ganadería y labranza son importantes, de la organización y administración del trabajo tradicional a una nueva donde la llegada de trabajadores y directores españoles es primordial, en fin de la producción en pequeña escala a la gran producción mercantil. Los componentes, en suma de esta transformación serían: la creciente inversión de capitales en el cambio del paisaje agrario, la formación de sociedades anónimas, la asociación a empresarios y capitales extranjeros, el asalto irrestricto sobre los recursos naturales y la subordinación del campo a la ciudad.

En este escenario, el lago comienza a desaparecer de las representaciones geográficas para ceder su lugar a las haciendas modernizadas. Por ello vemos surgir levantamientos topográficos como los del ingeniero civil Fernando de Rosenzweig, Serapio Echeverría, Romualdo Rivera y algunos otros levantaron varios planos de las haciendas del Estado de México en

39 AHCarso.CDLIV.2a.1906.13.81 /f.3.

40 Auguste Genin. Notes sur le Mexique 1908. México, 1910 y AH-Paribas 610 FOM.221.326 Mexico le 28 Août 1914. 
el último tercio del siglo XIX. Allí observamos un paisaje donde el cartógrafo nos muestra escalas erróneas y muy diversas, falta de puntos de localización, ausencia de leyendas. El espacio es visto como una serie de puntos que dificultan su lectura. Los trazos de los ríos se confunden con los de las barrancas, los de los linderos con los de los caminos.

En 1895 Antonio Guzmán hace un mapa de la hacienda de Zoquiapan (mapa 4). Allí encontramos, lo que consideremos es el preludio de la modernidad. La hacienda aparece ahora representada como en una fotografía con sus leyendas claras, sus escalas bien establecidas y sus espacios representados en forma tan nítida que el lector adivina cuáles son las tierras de cultivos, cuáles las de monte, cuáles los caminos. La pregunta que nos hacemos es por qué si siempre habíamos representado el paisaje como un conjunto de líneas y puntos, al finalizar el XIX aparecen nuevas representaciones casi fotográficas. La primera respuesta que nos surge es que ahora el espacio no es neutro sino que es una representación de la acción del hombre, de su control sobre la naturaleza.

\section{Mapa 4}

Plano topográfico de la Hacienda de Zoquiapan, 1895

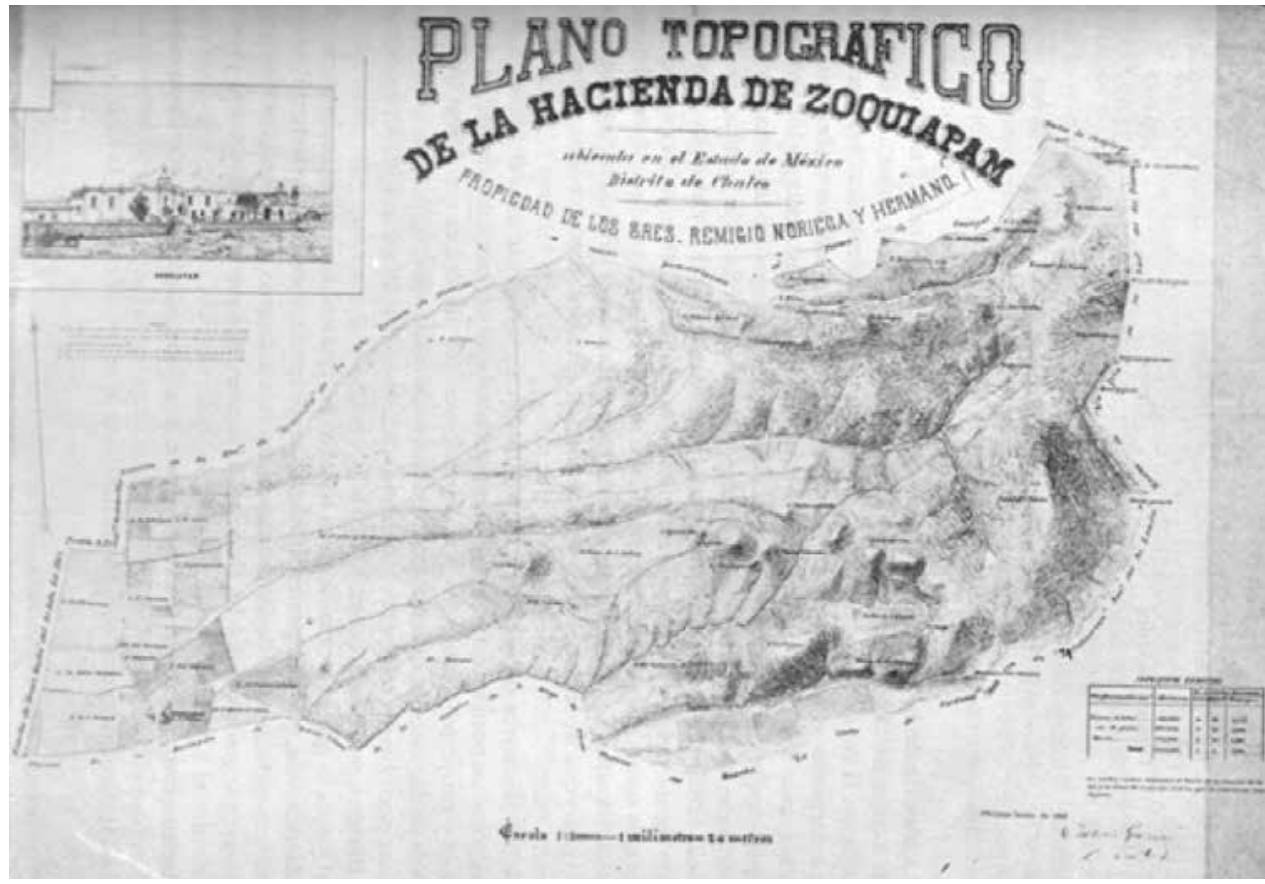

Fuente: AGN. Fototeca. 
La acción de la hacienda de Xico es un ejemplo elocuente. El espacio de líneas y de puntos cede su lugar a otro donde el control de la naturaleza por el hombre se representa en los espacios drenados de la laguna, en la construcción de líneas férreas, en la inserción del territorio de las haciendas sobre las montañas.

Aquí vemos, en efecto, que se había iniciado un proceso de cambios en el agro mexicano que hacen que el ojo del topógrafo vea la dimensión económica de las grandes propiedades. Empezamos a ver cómo aparece un agente que controla, que fiscaliza, que quiere contar y medir para controlar. Estamos frente a un proceso modernizador que permite que los Estados miren a la naturaleza de otra forma y que deja su huella en la representación del paisaje. En palabras de Scott ${ }^{41}$, el Estado premoderno es parcialmente ciego en calcular la riqueza, en establecer la propiedad y la productividad de la tierra, en localizar e identificar a propiedades y gente; en cambio el moderno establece mapas detallados del territorio y la gente creando apellidos permanentes, estandarizando las pesas y medidas, fijando catastros y censos, diseñando ciudades, organizando transportes y así sucesivamente. Esto es, lo que vemos en la transición de los mapas de Rosenzweig al de Guzmán y al de la acción de Xico. Un mapa que hace legible los recursos físicos y de los espacios más productivos, que sirve para tener más conocimiento de las sociedades, para inventariar la tierra, la gente, los ingresos.

Muestra de estos esfuerzos modernizadores aparecen en las fotografías de las haciendas que dan cuenta de esa revolución agrícola que hemos mencionado. Ahora, los actores son las milpas con sus excepcionales rendimientos, los arados, las desterronadoras americanas, las desgranadoras de maíz, las sembradoras, las trilladoras, el establo para 800 vacas de ordeño, las máquinas para fabricar quesos y mantequillas, los talleres para almacenar arados y máquinas.

En la parte hidráulica observamos las tierras desecadas de la laguna con sus bordes, las presas o depósitos de agua para regar terrenos, las obras de canalización del lago, los tajos como el de San Isidro.

41 James Scott, Seeing like a state. How certains schemes to improve the human condition have failed. (New Haven \& London: Yale University Press, 1998), 46-48. 
Finalmente en materia de transportes ya no vemos solo a los vapores que navegaban por los canales de Chalco y a sus trajineras, sino que el Ferrocarril de Xico y San Rafael, el de Río Frío, las impresionantes locomotoras, la estación de ferrocarril con arbustos y enredadera son muestras de la modernidad. El paisaje de lagos, pueblos y montañas se diversifica y aparecen los sistemas ferroviarios, las impresionantes compañías agrícolas e industriales.

\section{ConClusión}

Intentamos mostrar los cambios en el paisaje en Chalco-Amecameca entre la época colonial y el siglo XX. Estos los resumimos en las transformaciones acarreadas por una revolución agrícola y un modelo empresarial industrial que transforma las condiciones ambientales en la cuenca de México. En esa explicación observamos cómo desaparece un lago extraordinariamente pródigo donde existían 14 variedades de peces y cada año varios millones de pájaros lo visitaban. Analizamos los cambios en el paisaje de Chalco-Amecameca a través del mirador de los canales. De los canales prehispánicos multifuncionales que servían para transportar mercancías, para irrigar las chinampas de los vecinos y para el tráfico de personas, pasamos, en la época colonial, a los proyectos para drenar los humedales y los espacios lacustres y reducir la utilidad de los canales a simples medios de irrigación y de transporte. No será sino hasta finalizar el siglo XIX cuando observemos que se drenan los espacios lacustres y los canales se convierten en simples medios de irrigación dejando el transporte de mercancías y de hombres a los nuevos sistemas ferroviarios.

Con esta transformación también se altera el paisaje de la cuenca. Un paisaje diverso, integrado por una superficie forestal de ahuejotes, árboles que sirven para apuntalar los camellones donde se practica la agricultura chinampera altamente productiva, donde los promontorios chinamperos muestran el cultivo de maíces y hortalizas, donde los canales y las superficies lacustres ofrecen el medio de reproducción de cardúmenes de peces, anfibios, víboras y diversas especies de aves que visitan periódicamente los lagos; con la desecación se convierten en paisajes uniformes destinados al monocultivo del maíz. La diversidad paisajística de los canales prehispánicos se convierte en la uniformidad del porfiriato. Se pierde la cubierta 
forestal, los peces y anfibios, las aves migratorias y el espacio se uniforma con el monocultivo del maíz. El escenario de los lagos nos muestra que la historia humana es una lucha constante contra una naturaleza opresora que impone sus relieves físicos y sus suelos lodosos a la construcción de los canales: los ríos se domestican, la fauna desaparece, los cultivos empobrecen los suelos.

La lectura del paisaje se convierte así, es un medio de intercambio entre el hombre y la naturaleza; como la moneda, sin valor intrínseco pero potencialmente sin límites de evaluación. El paisaje como significado y significante, a la vez lugar concreto y su simulacro, al mismo tiempo marco y lo que contiene el marco. Querer conocer nuestra razón paisajística, tanto como la de otros medios, es querer manejar de una mejor manera las motivaciones que nos impulsan a transformar el paisaje, es querer acondicionar nuestro mundo con más medida, con más razón y las razones del paisaje de Chalco-Amecameca que hemos presentado son una muestra de ello.

\section{Bibliografía}

\section{Archivos}

AGN Archivo General de la Nación.

AHTSJDF Archivo Histórico del Tribunal Superior de Justicia del Distrito Federal.

CEH-CARSO Centro de Estudios de Historia de México Grupo Carso.

NORIEGA LASSO Paper's. Nettie Lee Benson Library. University of Texas-Austin.

Alzate y Ramírez, José A. "Proyecto para el desagüe de la laguna de Tescuco, 1767’. en El territorio mexicano. México: IMSS, 1982.

----. Gaceta de Literatura de México. México-Puebla.

\section{Artículos y libros}

Bairoch, Paul. De Jericho a Mexico. Villes et économie dans l'histoire. Arcades: Gallimard, 1985.

102 Bernecker, Walther L. De agiotistas y empresarios. En torno de la temprana industrialización mexicana. México: UIA, 1992.

Bernecker. Schmuggel. Illegale handelspratiken in Mexico des 19. (1988). 
Calvo, Thomas. Por los caminos de Nueva Galicia. Transportes y transportistas en el siglo XVII. México: Universidad de Guadalajara, 1997.

Coatsworth, John. El impacto económico de los ferrocarriles en el porfiriato. México: Era, 1984.

Coatsworth. Los orígenes del atraso. Nueve ensayos de historia económica de México en los siglos XVIII y XIX. México: Alianza, 1990.

Davis, Keith. "Tendencias demográficas urbanas durante el siglo XIX en México”. Historia Mexicana (1972).

Derry, T. K. y Trevor I Williams eds. Historia de la tecnología desde 1750 hasta 1900. México: Siglo XXI, 1977.

Durán, Juan Manuel. “Los proyectos de construcción de canales en el México de la segunda mitad del siglo XIX”. En Relaciones. 4. (1983): 96-106.

Espinosa, Gabriel. El embrujo del lago. El sistema lacustre de la cuenca de México en la cosmovisión mexica. México: UNAM, 1996.

Flores Clair, Eduardo. "Reseña sobre Clara Elena Suárez Argüello (1997)”. http://www.h-mexico.unam.mx (29.08.2005).

Florescano, Enrique. Breve historia de la sequía en México. México: Conaculta, 2000.

Florescano. Precios del maíz y crisis agrícolas en México. México: El Colegio de México, 1969.

Florescano. "Las sequías en México: historia, características y efectos”, en Comercio exterior. 30. 7. (1980): 747-757.

Genin, Auguste. Notes sur le Mexique 1908. México, 1910.

Gibson, Charles. Los aztecas bajo el dominio español. México: Siglo XXI, 1967.

Haber, Stephen. Industria y subdesarrollo. El proceso de industrialización en México. México: Alianza, 1992.

Hassig, Ross. Comercio, Tributo y Transportes. La economía política del valle de México en el siglo XVI. México: Alianza editorial, 1990.

Kip. “El transporte y la construcción, 1300-1800”. En Historia de la tecnología. La técnica en Occidente de la prehistoria a 1900. Editado por Kranzberg y Pursell. España: G. Gili, 1981.

Kranzberg, M. y Pursell, C. Eds. Historia de la tecnología. La técnica en Occidente de la prehistoria a 1900. España: G. Gili, 1981.

León Portilla, Miguel. Antiguas obras hidráulicas en América. España: MOPT, 1988. 
Lemeunier, Pérez Picaso et al. Agua y Modo de Producción. Barcelona: Crítica, 1990.

Musset, Alain. El agua en el valle de México. México: Pórtico de la Ciudad de México y CEMCA, 1992.

Martínez, Lucía. "Máquinas, naturaleza y sociedad en el distrito de Chalco, Estado de México a finales del siglo XIX". En Tierra, agua y bosques: historia y medio ambiente en el México Central. Coord. Alejandro Tortolero, México: CEMCA-I. Mora- UdeG, 1996.

Orozco y Berra Manuel. Geografía de las lenguas y carta etnográfica de México. México: J.M. Andrade, 1864.

Orozco y Berra, Manuel. Memoria para la Carta Hidrográfica del valle de México. México, 1864.

Ortiz de la Tabla, Javier. Comercio Exterior de Veracruz, 1778-1821. España: EEHA, 1978.

Palerm, A. México Prehispánico. Evolución ecológica del valle de México.

México: Conaculta, 1990.

Payno, Manuel. Los bandidos de Río Frío. México: Porrúa, 1968.

Pérez Picasso Lemeunier et. al. Agua y Modo de Producción. Barcelona: Crítica, 1990.

Pinon. Un canal, des cannaux. Paris: Ed A \& J Picard, 1986.

Quiroz, Enriqueta. Entre el lujo y la subsistencia. Mercado, abastecimiento y precios de la carne en la Ciudad de México, 1750-1821. México: El Colegio de México- I. Mora, 2005.

Romano, Ruggiero. Monedas, seudomonedas, circulación monetaria en las economías de México. México: Fondo de Cultura Económica, 1998.

Scott, James. Seeing like a state. How certains schemes to improve the human condition have failed. New Haven \& London: Yale University Press, 1998.

Sierra, Carlos J. Historia de la navegación en la Ciudad de México. México: DDF, 1968.

Suárez Argüello, Clara Elena. Camino real y carrera larga. La arriería en Nueva España durante el siglo XVIII. México: CIESAS, 1997.

Tortolero, Alejandro. De la coa a la máquina de vapor: actividad agrícola e innovación tecnológica en las haciendas de la región central de México, 1880-1914. México: Siglo XXI, 1995.

104 Tortolero, Alejandro. (Coord.). Tierra, agua y bosques: historia y medio ambiente en el México Central. México: CEMCA-I.Mora-UdeG, 1996. 
Tortolero, Alejandro. "Los caminos de agua en la producción y en la producción y el comercio en el Sureste de la Cuenca de México en la segunda mitad del siglo XVIII". En Esfuerzos y fracasos de la modernización en México: De las reformas borbónicas al porfiriato, ed. R. Liehr. Madrid - Frankfurt am Main: Iberoamericana, 2006.

Tortolero, Alejandro. Notarios y agricultores. Crecimiento y atraso en el campo mexicano, 1780-1920. México: Siglo XXI, 2008.

Para citar este artículo: Tortolero Villaseñor, Alejandro. "Canales de riego y canales navegables en la cuenca de México: economía, patrimonio y paisaje en el México porfirista", Historia Caribe Vol. X No. 26 (Enero-Junio 2015): 75-105. DOI: http://dx.doi.org/10.15648/hc.26.2015.4 